\title{
Research on the Risk Control of Peer-to-Peer Lending Platform based on IDEFO Method
}

\author{
Jianxin $\mathrm{Bi}^{\mathrm{a}}$, Jianying Tian ${ }^{\mathrm{b}}$ \\ Department of Finance and Statistics, Zhejiang Wanli University, Ningbo 315100, China. \\ agreygirl0511@126.com, btianjianying@163.com
}

Keywords: P2P network lending, risk Management, IDEF0.

\begin{abstract}
In recent years, the rapid growth of P2P lending platform, while the risks have become increasingly apparent. Because of its speed of development with the appropriate regulatory presents a reverse trend, leading to increasing problems platform. Because of the multi-level and diversified characteristics of risk factors of $\mathrm{P} 2 \mathrm{P}$ platform, risk control should not only be based on inherent rules of development of $\mathrm{P} 2 \mathrm{P}$ platform, but also apply the correct method to analyze and process complex risk systems. By using IDEF0 method, a complex system model of P2P lending risk management is established, and the risk analysis of $\mathrm{P} 2 \mathrm{P}$ platform is more systematic and hierarchical, so that it can be systematized, layered, multi-perspective and focused on risk monitoring of P2P loan platform and put forward preventive and regulatory measures.
\end{abstract}

\section{Introduction}

The development of P2P online lending solves the financing problems of some small and medium investors and small and micro enterprises, and then promotes the development of the real economy. However, due to the brutal growth of P2P platforms in recent years, government regulation cannot keep up with The Times, resulting in many risk events such as the failure of a large number of P2P platforms, the disappearance of businessmen and the fraud of platform etc. According to the platform data from "online loan home", P2P platforms have been developing well in recent years, and the main problems are: disappearance, withdrawal difficulty, closure and economic investigation. Among them, the proportion of "disappearance" and "withdrawal difficulty" is close to $90 \%$ of the platform problems, and they also are the two cases which investors have lost a lot of money. These problems have seriously affected the healthy development of P2P online lending. Therefore, it is of great theoretical and practical significance to strengthen the research on risk control of $\mathrm{P} 2 \mathrm{P}$ online lending.

At present, many scholars have studied the risk control of $\mathrm{P} 2 \mathrm{P}$ platforms, mainly focusing on the following two aspects: The research on risk control of P2P platform from micro perspective. According to the transfer cost and cost reduction strategy of cost control theory. Zhou hui ${ }^{[1]}$ uses the contract theory to analyze the performance mechanism of P2P lending transaction process and the three operational modes and potential risks of domestic $\mathrm{P} 2 \mathrm{P}$ online lending platforms and puts forward the corresponding risk control strategy from the perspective of industry self-discipline and supervision. Based on macro perspective, there are researches on risk control from the perspective of supervisory authorities. He qiaoli[2], Zhong fengying[3] and Ma qiang[4] use the experience of foreign P2P platform supervision, and put forward the risk control strategy from the legal, credit system and the organizational structure of the network loan enterprise etc. Peng yan and Yue jingui[5]use the fish-stab diagram model to identify the risk factors in the current P2P lending industry and put forward the risk control strategy according to the actual development situation. To sum up, this paper believes that many factors are macroscopic in the emergence of $\mathrm{P} 2 \mathrm{P}$ problems, therefore, it is advisable to integrate micro-level research into macro-level research and systematically study the P2P lending risk.

In consideration of the above risk problems in current $\mathrm{P} 2 \mathrm{P}$ online lending platforms and relevant scholars' research on the risk theory of $\mathrm{P} 2 \mathrm{P}$ online lending [6], this paper constructs the model of P2P lending risk management system using IDEF0 method in combine with existing research on internet 
finance and $\mathrm{P} 2 \mathrm{P}$ lending market. This paper takes the influencing factors of $\mathrm{P} 2 \mathrm{P}$ online lending risk and the accessory pathway as a "system" to study. This reveals the correlation between the influencing factors rather than the uniqueness, overall importance rather than one-sidedness, systematicness rather than scattered property. In this paper, we try to form a complete theoretical analysis framework for the risk generation of $\mathrm{P} 2 \mathrm{P}$ platforms with the systemic-overall perspective. The structure of this article is as follows: The second part is the overview of IDEF0, the third part is to build a model of P2P platform risk system based on IDEF0 method, the fourth part is conclusion and suggestion.

\section{The overview of IDEF0 principle}

IDEF [7] is a system analysis and design method developed by the United States air force in the late 1970s and early 1980s on the basis of the structural analysis and design method of the ICAM project (Integrated Computer Aided Manufacturing engineering). It has the advantages of reducing system errors and project development costs, while enhancing the consistency of management objectives. IDEF features are as follows: (1) It is a relatively open and complete system and the system has IDEF0, IDEF1x, IDEF2,..., IDEF14, and the system is still in continuous improvement. (2)Modeling and analysis from functions, information, objects and other different perspectives of complex systems, (3) The system can capture the main features of complex systems and giveaway secondary details.

The IDEF0 method is one of the IDEF contents, the basic principle of IDEF0 is the structural analysis method, which describes and understands a system comprehensively by establishing a model, and then can express a system that meets the requirements and functions. IDEF0 method has the following characteristics: (1) Provide a powerful system for description, analysis and design methods. (2)Each model has a purpose (why build a model?) and a point of view (what is the person's position to analyze the problem?), and can distinguish the difference between function and implementation. (3)The decomposition from top to bottom. (4) Strict staff relations, review procedures and document management methods. The above four points constitute the foundation of the IDEF0 method, and they complement each other and losing one, which will reduce the effectiveness of the IDEF0 method.

\section{Build model of P2P platform risk management system based on IDEF0 method}

Using the IDEF0 method to construct the complex system model of risk management of P2P platform and adopt the method of "from top to bottom and decomposed layer by layer" to make the thinking clear; When implementing P2P risk management, adopt the method of "from bottom to top and step by step" to make it staging. According to the requirements of the IDEF0 method, the first is to establish A-0 diagram, and then decompose step-by-step according to A-0 diagram. The specific steps are as follows.

\subsection{Build figure A-0.}

Fig. 1 is used to describe the internal and external relations of $\mathrm{P} 2 \mathrm{P}$ risk management system. Among them, I1 is the research report of $\mathrm{P} 2 \mathrm{P}$ platform; $\mathrm{C} 1, \mathrm{C} 2, \mathrm{C} 3, \mathrm{C} 4$ are: relevant national policies and regulations, industry policies and regulations, financial policies and regulations and the management documents and rules of P2P platform; M1, M2, M3, M4 and so on are: state regulatory agencies, financial regulators, industry self-regulatory organizations, P2P platforms, central banks, CBRC, CSRC, provincial regulatory authorities, third-party payment platforms, credit rating agencies and ministry of industry and information and ministry of public security; 01, 02, 03 are: industry and regulatory documents, risk management database and high-quality $\mathrm{P} 2 \mathrm{P}$ platform. Figure 1 shows that the $\mathrm{P} 2 \mathrm{P}$ risk management system is controlled by $\mathrm{C} 1 \mathrm{C} 2 \mathrm{C} 3 \mathrm{C} 4$, and carries out the supervision, control and transformation of I1 with the help of M1 M2 M3 M4 and other mechanisms. Finally, it will output various regulations and regulatory documents, risk management databases and high-quality P2P platforms. 


\subsection{Build fig.A0.}

According to the law of $\mathrm{P} 2 \mathrm{P}$ risk management system, A-0 diagram is decomposed into different activity module from the four perspectives of the rigid payment risk, and the legal and regulatory risk, the reputational risk and the risk of P2P platform control system. As shown in fig.2.

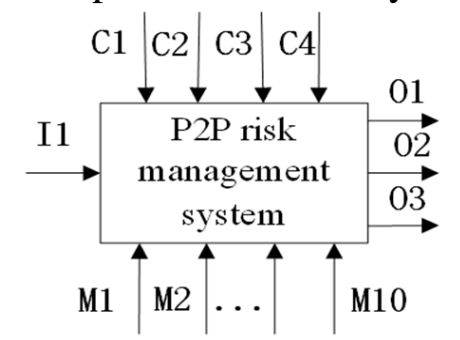

Fig.1P2P risk management system

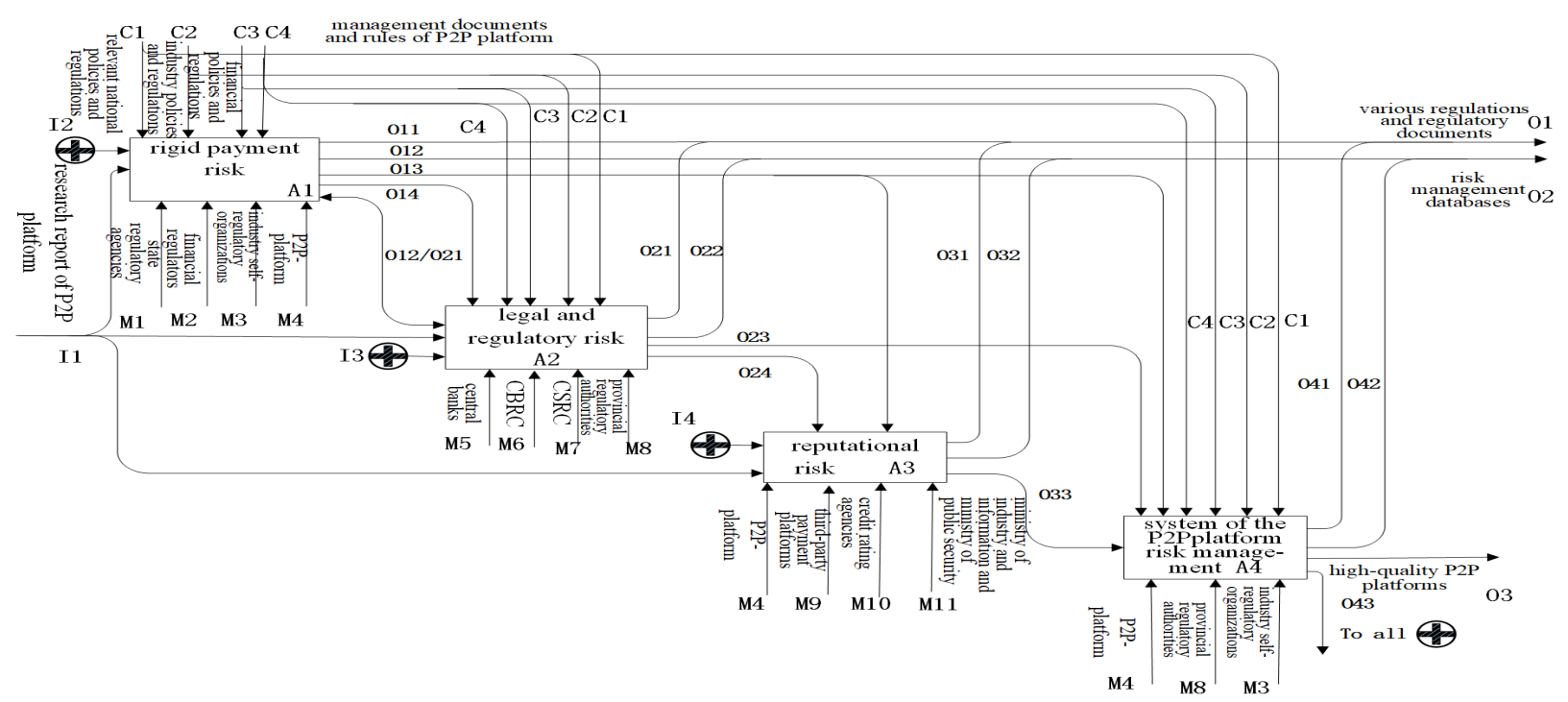

Fig.2 The complex system of the P2P platform risk management (Fig.A0)

Among them, I2, I3 and I4 are the rigid payment risk, the legal and regulatory risk, the reputational risk and the feedback information of P2P platform control system respectively.O12 and O21 provide feedback information from reciprocal control between the rigid payment risk, and the legal and regulatory risk, $\mathrm{O} 23$ is the information from the $\mathrm{P} 2 \mathrm{P}$ platform risk control system with the use of legal and regulatory risk, $\mathrm{O} 24$ is the information from the reputational risk with the use of legal and regulatory risk, 033 the information from the $\mathrm{P} 2 \mathrm{P}$ platform control system that after controlling the rigid payment risk and the legal and regulatory risk, the reputational risk applied to the $\mathrm{P} 2 \mathrm{P}$ platform control system. Other symbolic meanings are the same with fig.1.

Fig. 2 shows that I2 I3 I4 is the module information that come from the risk control system of P2P platform, namely $\mathrm{O} 43$, which feedbacks to each activity module again; the output information of $\mathrm{O} 11$, $\mathrm{O} 21, \mathrm{O} 31, \mathrm{O} 41$ is integrated into $\mathrm{O} 1$, the industry and regulatory documents; the output information of $\mathrm{O} 12, \mathrm{O} 22, \mathrm{O} 32, \mathrm{O} 42$ is integrated into $\mathrm{O} 2$, which is the risk management database. Refer to figure 2, the Internet financial or P2P regulators can clearly understand what the risks are and how risky they are, so we can find out and make up the loopholes and deficiencies of Internet financial regulation.

\subsection{The decomposition process of Figure A0.}

The fig. A0 can be decomposed into A1, A2, A3 and A4.

(1)The decomposition figure A1 of rigid payment risk.

First is to decompose the module of rigid payment risk in fig.2, and should follow principle of input (I), output (O), control (C) and mechanism (M) of the fig.A0. As shown in fig.3, the A1 activity module can be decomposed into the activity module of credit risk A11, market risk A12 and liquidity risk A13. Among them, the output of credit risk $\mathrm{O} 113$ and $\mathrm{O} 114$ respectively act on the input information of market risk and liquidity risk, and the output $\mathrm{O} 123$ of market risk acts on the input 
information of liquidity risk. O111, O121 and O131 are the output information of credit risk, market risk and liquidity risk respectively, and are integrated into $\mathrm{O} 1$, that is, the information on regulatory and legal regulatory documents. $\mathrm{O} 112$, $\mathrm{O} 122$ and $\mathrm{O} 132$ are the output information of credit risk, market risk and liquidity risk respectively, and are integrated into $\mathrm{O} 2$, that is, the information of risk management database. Other symbolic meanings are the same as fig.1, fig.2. Referring to fig.3, the Internet financial regulatory authorities can clearly understand what aspects of the rigid payment risk are, and what are the effects of these aspects on rigid payment risk? So that we can find out the reason and take corresponding measures to make up for more loophole of rigid payment risk in P2P platform.

(2)The decomposition figure A2 of legal and regulatory risk

We decompose the module of legal and regulatory risk in fig. 2 with following the principle of the input, output, control and mechanism of A0. As shown in fig.4, the A2 activity module can be decomposed into two modules: legal risk A21 and regulatory risk A22. Among them, O213 is the feedback information from reciprocal control process between legal risk and regulatory risk. O211 $\mathrm{O} 212$ and $\mathrm{O} 221 \mathrm{O} 222$ are the output information of legal risk and regulatory risk respectively, and $\mathrm{O} 211$ and $\mathrm{O} 221$ are integrated into $\mathrm{O} 1$, which is the regulatory document information, $\mathrm{O} 212$ and $\mathrm{O} 222$ are integrated into $\mathrm{O} 2$, that is, risk management database information. Other symbolic meanings are the same as fig. 1 to 3. Refer to fig.4, the Internet financial regulators can clearly understand the legal and regulatory risks from what respect, how to through the relevant regulatory authorities to formulate strategies to control the risk. So that we can find out the causes and take corresponding measures to remedy the loopholes in the legal and regulatory risks.

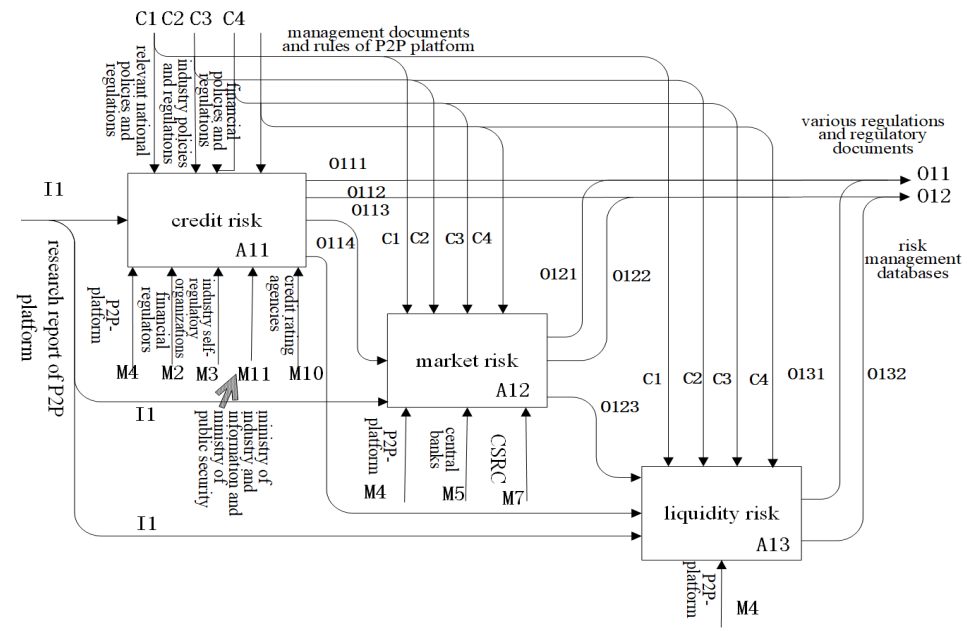

Fig.3 The decomposition figure A1 of rigid payment risk

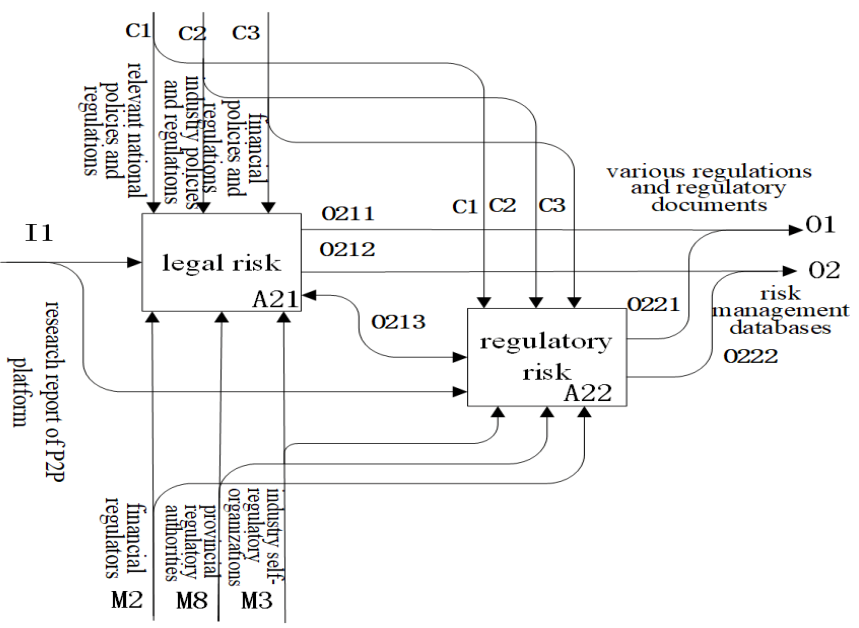

Fig.4 The decomposition figure A2 of legal and regulatory risk 
(3) The decomposition fig.A3 of reputational risk

We decompose the module of reputational risk in fig. 2 with following the principle of the input, output, control and mechanism of A0. As shown in fig.5, the A3 activity module can be decomposed into three modules, namely trust risk A31 operational risk A32 and non-operational risk A33.

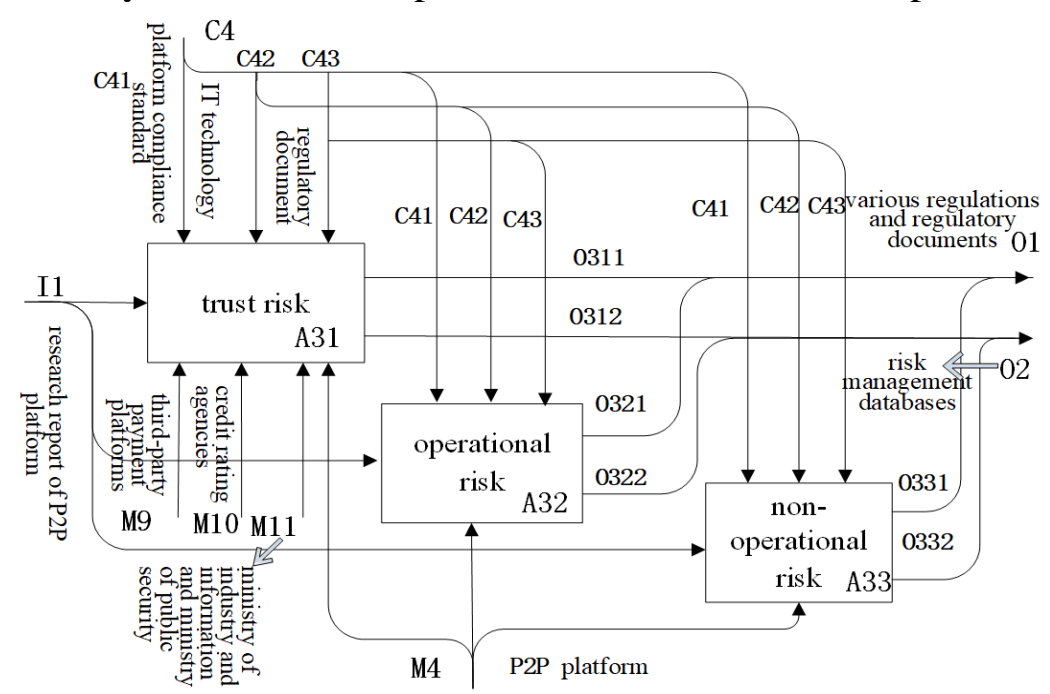

Fig.5 The decomposition figure A3 of reputational risk

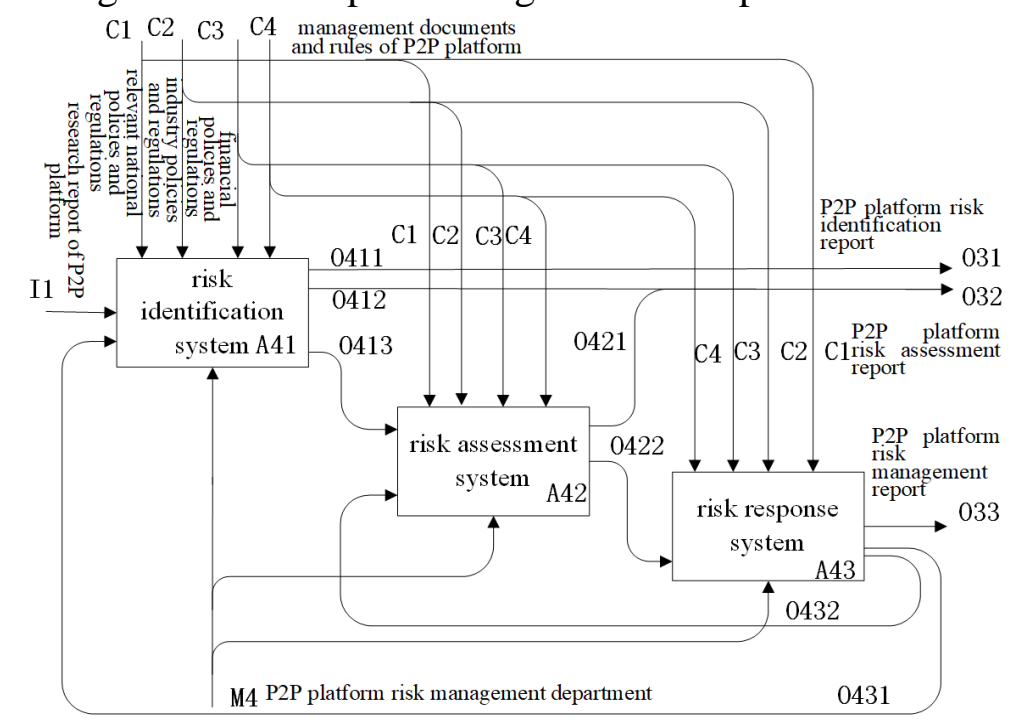

Fig.6 The decomposition figure A4 of P2P platform risk management system

The trust risk module, operation risk module and non-operational risk module are mainly operated by the P2P platform through its own platform compliance standard C41, IT technology C42 and the regulatory document $\mathrm{C} 43$. O311, O312, O321, O322, O331 and $\mathrm{O} 332$ are output information of trust risk, operational risk and non-operational risk respectively, among them, O311 O321 and O331 are integrated into O1, namely, regulatory and regulatory documents, $\mathrm{O} 312 \mathrm{O} 322$ and $\mathrm{O} 332$ are integrated into $\mathrm{O} 2$, that is the information of risk management database. Other symbolic meanings are the same as fig.1 to 4. Refer to fig.5, the Internet financial regulators can clearly understand the reputational risks from what respect, how to use the normal operation of $\mathrm{P} 2 \mathrm{P}$ platform to control the risk and take appropriate measures to make up for the loopholes of reputational risk.

(4) The decomposition fig.A4 of risk control system of P2P platform

We decompose the module of risk control system of $\mathrm{P} 2 \mathrm{P}$ platform in fig.2 with following the principle of the input, output, control and mechanism of A0. As shown in fig.6, the A4 activity module can be decomposed into three modules of risk identification system A41, risk assessment system A42 and risk response system A43. O413 is the output information of the risk identification system A41 acts on the input information of the risk assessment system A42. O422 is the output information of the risk assessment system A42 acts on the input information of the risk response system A43. O412 and 
O421 are the output information of the risk identification system and the risk assessment system respectively, they are integrated into $\mathrm{O} 32$, that is, the information of the $\mathrm{P} 2 \mathrm{P}$ platform risk assessment report, $\mathrm{O} 431$ is the feedback control information of the risk response system to the risk identification system, and $\mathrm{O} 432$ is the feedback control information that risk response system acts on risk assessment system. Other symbolic meanings are the same as fig.1 to 5. According to fig.6, P2P platforms can clearly understand the various risks of platform operation, and to carry out risk management of $\mathrm{P} 2 \mathrm{P}$ platforms by identifying risks and controlling risks; at the same time, the Internet regulatory authorities can clearly understand in what areas are prone to have risks and take corresponding measures to supervise and manage $\mathrm{P} 2 \mathrm{P}$ platforms.

\section{Conclusion and prospect}

Based on the IDEF0 method, this paper constructs a complex system of P2P risk management, which provides a new idea for the study of P2P risk management. It overcomes the disadvantage that the development speed and supervision progress of P2P platform cannot keep up with The Times. Through the IDEF0 system model, we can carry out systematic supervision policies and countermeasures at a certain level. Due to space constraints, this article cannot proceed to the next level of refinement decomposition. In the future research, it is possible to refine and decompose each layer, and establish the corresponding system graph's document file and risk management database.

\section{Acknowledgments}

This paper is one of the periodic results of "the study of risk control of P2P lending platform - take Zhejiang as an example(2016C35049)" of Zhejiang province's soft science research project in 2016, is one of the periodic results of "the research on the path and countermeasure of the internet finance in supporting Ningbo real economy development(201701HJ-C01244)" in the 2017 Ningbo soft science project; is 2015 Zhejiang natural science fund project, which is the "research on the financial virtuous circle mechanism of the new agricultural business entity in Zhejiang province(LY15G030011)."

\section{References}

[1]. Zhou Hui. P2P Network Lending: Implementation Mechanism, Operation Mode and Risk Control.West China Finance.vol.12(2014)No12, p. 19-24.

[2]. He Qiao-li. On Regulation of Domestic Internet Finance: A Case Study of P2P Platform Regulation. Journal of Lanzhou Institute of Technology.vol.23(2016)No.3, p. 100-103.

[3]. Zhong Feng-ying.The Study on Risk and Countermeasures in P2P Financing Mode.Journal of Beijing College of Finance and Commerce.vol.31(2015)No.2, p. 13-16.

[4]. Ma Qiang,Wang Jun.The General Situation, Problems and Future of P2P Lending in China. Finance \& Economics.vol.8(2016)No.8, p. 14-24.

[5]. Peng Yan,Yue Jin-gui.Rearch on the Risk Identification and Control of Peer-to-Peer Lending Based on Fishbone Model. Journal of WUT(Information \& Management Engineering). vol.38(2016)No.5, p. 561-564.

[6]. Shen Xiao-mei,Bi Jian-xin.Research on Risk Management of P2P Network Loan Platform: Taking Zhejiang Province as an Example.Journal of Zhejiang Wanli University. vol.31 (2018) No1,p.27-31.

[7]. Chen Liu-yu, IDEF modeling analysis and design method. Tsinghua University Press, 2000年, p.1-98. 